\title{
The Efficacy of Using Liulishuo for Spoken English Ability-Taking the Practice of Liulishuo in North China Electric Power University (Baoding) as an Example
}

\author{
Liu Yang ${ }^{1}$, Yang Tong ${ }^{1} \&$ Xu Siyuan ${ }^{1}$ \\ ${ }^{1}$ Department of English, North China Electric Power University (Baoding), Hebei, China \\ Correspondence: Liu Yang, Department of English, North China Electric Power University (Baoding), Hebei \\ 071000, China.
}

Received: November 8, 2018

Accepted: December 23, 2018

Online Published: March 25, 2019

doi:10.5539/ies.v12n4p244

URL: https://doi.org/10.5539/ies.v12n4p244

\begin{abstract}
This research aims to verify the effectiveness and practicability of Liulishuo, an English-learning APP, in improving college students' oral English. The research adopts different student groups according to their different listening levels, and compares the scores of the pre- and post-practice tests of the control groups and the feedback analysis of the two sessions. The research results showed an upward trend, which proved the efficacy and practicability of Liulishuo in improving students' oral English.
\end{abstract}

Keywords: efficacy, Liulishuo, spoken English

\section{The Rise and Development Trend of Mobile-APP-Assisted English Learning}

\subsection{The Rise of Mobile-APP-Assisted English Learning}

Mobile learning, a new form of learning that conducts learning through communicating with others, means that learners can obtain educational information, resources and services from wireless devices and mobile devices (such as mobile phones, PDAs with wireless communication modules, Pocket PCs, and handheld e-book readers) and wireless communication networks anytime and anywhere they need to learn. And APP, which is the abbreviation of application and the general term for the mobile phone software, mainly refers to the third-party program installed on the smartphone. Mobile APPs are widely used in our daily life, and have a significant influence on English education and learning.

With the popularity of $4 \mathrm{G}$ networks, various types of convenient mobile devices have flooded into the air, making all resources at our fingertips. Featuring "rich in materials, easy to operate and convenient to use", the implementation of APPs in the market has already led to a major reform of the education field, and students can learn English independently. The problem is that, based on the aid of multimedia, the analysis of the actual efficacy of using English APPs for Chinese college students' spoken English namely pronunciation, intonation, re-reading and continuous reading is still insufficient in research.

\subsection{The Development Trend of Mobile-APP-Assisted English Learning}

\subsubsection{The Development Trend in Foreign Countries}

At the end of the 20th century, the concept of mobile learning gradually entered people's field of vision. C. O'Malley believes that "mobile learning is any form of learning that is not fixed and pre-arranged, or that learners use learning opportunities offered by mobile technology." (Huang, 2008) It is based on informal learning theory. Emphasizing the ubiquity of learning, it is the latest learning concept that refers to the use of clip time outside the work and study and the non-systematic learning with mobile devices such as smartphones anytime and anywhere. Different from systematic curriculum learning, mobile learning emphasizes micro-learning content and self-learning, which can meet the needs of fragmented and personalized learning and is an innovation of teaching and learning strategies.

At present, research on mobile learning abroad is mainly done in some developed countries in Europe and North America. Some mobile learning researches have started for 2-3 years. According to the purpose, they can be mainly divided into two categories, one initiated by the current E-Learning provider, which seeks to draw on the experience of E-Learning to bring M-Learning to market and use it more for corporate training and the other one 
initiated by educational institutions who try to improve teaching, learning and management through new technologies based on school education. Although the research on mobile learning is not long, its development is rapid in terms of current research progress and it involves a wide range and a variety of forms. The new technologies, new ideas and new methods embodied in the research are worth learning. (Liu \& Ru, 2004)

\subsubsection{The Development Trend in China}

With the relevant materials at home and abroad, we have obtained the following analysis of the research status in this field: In recent years, the oral learning approach has gradually changed from the cramming teaching model to the inspiration of students' interest, and self-learning. At the same time, social education institutions have opened up many resources for students, from which MOOC, "flip classroom" and "anchor" teaching methods and others derive. But it is worth noting that on the stage of the 21 st century, the Internet plays a role that cannot be ignored. According to China Internet Center (CNNIC) statistics, by the end of June 2014, the total number of mobile Internet users in China has reached 838 million, of which the mobile phone users were 527 million. And among mobile phone netizens, students account for a relatively large proportion of $24.9 \%$. Moreover, with the wide application of computer network technology, network-based autonomous learning has become an important learning method for college students. (CNNIC official website statistics, 2014) The Ministry of Education's "Learning and Teaching Reform Project for College Students" focuses on cultivating students' self-learning ability, and adopts modern information technology such as multimedia and internet to improve students' English comprehensive ability. As a result, the new learning method of spoken English APP has been favored by students.

The following specific examples can be very convincing to show that the use of mobile APP is flooding into the classroom learning of the new century. For example, Dou Juhua's Mobile Micro-learning Application Research Based on the following Smartphones (2014), mainly introducing the theory of mobile learning, and investigating the current situation of college students' mobile learning, which has reference value. (Dou, 2014) In addition, the use of the APP can help students solve specific problems. For example, domestic researchers mainly start from reading comprehension, and study the characteristics of Chinese students' style and nucleus of tone, intonation phrase division, prepositional proposition, rhythm pattern, etc., where students are prone to errors in these aspects. The use of APP enables students to self-check and correct themselves, find their own problems in a timely and accurate manner, and improve students' efficiency and initiative. However, Li Ying et al. conducted statistics and analysis on the study of oral English teaching in China in the past ten years (2000-2009) (Li \& Zhai, 2010) and the results show that the empirical research that helps students to develop oral extracurricular English training and improve their oral English is still too little. This shows that the emergence and use of APP is an improvement though with limitation.

As a new way of learning, the research space for spoken-English-practice APP has yet to be filled. Hou Yanfang's Learning with Mobile Tools (Hou, 2015) and other similar studies are only about the theory of mobile learning, but the research on impact of mobile English APP on college students' English learning is far from enough. Among them, Guo Mengshan's The Influence of Mobile APP on College Students' English Learning points out that at present, college students' using mobile APP to assist English learning has become a common phenomenon (Fei \& Guo, 2015).

With many unsolved problems in using APPs, it proves that this field remains to be explored. To start our research, we used specific questionnaires to determine the specific APP that students prefer and we chose the most favored one. Then we take the control experiment to improve the accuracy of the experimental results, and actual results are used to test the impact of a specific APP on each specific pronunciation of each participating student so as to record and analyze the data in details. This greatly compensated for the gaps in research on the use of APP-learning methods in oral learning so that this practice has practical values and significance in society.

\section{The Reasons for the Rise of Mobile Apps and How to Connect Them with English Learning}

\subsection{The Reasons for the Rise of Mobile Apps}

With the great development of society, 4G networks are at our fingertips, the software market is booming, and there are various ways to acquire learning resources. However, the new generation pursues convenient, fast and simple processing methods, so English APPs that meet their demands are more likely to be their choice for learning.

\subsubsection{The Main Functions}

The mobile APPs for assisting English learning is rich in materials, easy to operate and convenient to use. It combines with the concept of "flip classroom" to encourage students to learn English by themselves, focusing on 
the way of blending situations like dubbing to cultivate students' abilities of self-learning, self-examination and self-correcting of their own oral problems, and sharing communicating and displaying independently, improving students' learning efficiency, and enhancing learning interest and initiative. From the functions of these mobile APPs that assist in learning English, it can be seen that it has its own characteristics.

\subsubsection{The Attractive Features}

Firstly, accuracy. Users take the initiative to download general educational Apps according to their actual needs. Most educational APPs have the function to share accomplishments to social networking sites such as QQ, WeChat, and Weibo, which can attract people with similar interests. Secondly, easy to control. Liulishuo an English dubbing APP has video excerpts of less than 3 minutes, and there are dubbing materials of only one sentence of about 30-60 seconds, which will exhaust students' interest. Thirdly, quickness. Relying on the rapid development of $4 \mathrm{G}$ network, English APP, from the start of selection of dubbing materials to the share of the results, the web browsing is smooth, so are the sound and pictures, and in a blink, resources can be shared among tens of thousands of English learners.

\subsubsection{Autonomous Learning}

Under the 12-year compulsory education and the fixed "cramming" teaching mode, more and more Chinese students are under the pressure of test-taking and lose the ability to learn and explore independently. With the rapid development of the network and the rapid development of mobile technology, all the English-speaking practice resources at our fingertips are flooding into the classroom. Liulishuo, on the one hand, is rich in spoken English materials, like dubbing materials that contain dialogue segments used in various English communication scenarios. On the other hand, from page design, layout, operation control interface to actual file preservation and sharing, the APP is inspiring students to conduct autonomous learning and actively adopt learning method outside the classroom with its "listening", "speaking" and "reading" input and vivid colors of the dubbing materials.

\subsubsection{Independent Sharing}

Mobile phones are an indispensable important medium for enhancing the mutuality and sharing of information among students. Therefore, English APPs use mobile phones as carriers to provide an online platform for teachers and students where they can communicate, and timely and effectively publish English learning materials, and display students' real and effective classroom feedback conveniently and quickly. Also, they help students supervise each other and save time and effort to share online resources for English learning.

\subsection{The Relationship between the Characteristics of Liulishuo and English Learning}

\subsubsection{The Relationship between Liulishuo and English Learning}

The researchers found that during the two-month continuous use of Liulishuo to practice oral English, the supervisor can quickly and accurately discover the pronunciation problems of students through the dubbing materials sent by the students through mobile phone. For example, many students cannot meet the qualified standards for the pronunciation of diphthongs. The very simple words "now", "blind", "why", "clouds", etc. appearing in the dubbing can be accurately selected by the teacher, and the students' mistakes are analyzed word by word. There are also many single simple pronunciation problems that are undoubtedly revealed through dubbing.

Table 1. General survey before using Liulishuo

\begin{tabular}{lcc}
\hline Option & Subtotal & Proportion \\
\hline Can be downloaded to your phone for easy carrying & 330 & $81.08 \%$ \\
Can help me make plans and learn easily & 170 & $41.77 \%$ \\
Attractive & 68 & $16.71 \%$ \\
You can download a free APP to save money & 94 & $23.1 \%$ \\
Meet audiovisual needs & 173 & $42.51 \%$ \\
Have pictures to understand and memorize & 143 & $35.14 \%$ \\
Effective number & 388 & \\
\hline
\end{tabular}

In the feedback questionnaire after the research, we found that the students can accurately point out the detailed aspects of their pronunciation that need to be improved or are worth noting. This is reflected in the specific data result that $42.86 \%$ of the students improved their tone of voice, $21.43 \%$ improved in continuous reading, $14.29 \%$ 
improved in pronunciation and $7.14 \%$ of the students think that the tone, voice and their rate control are improved.

Based on a comparison of the prevailing surveys before using Liulishuo and targeted surveys after using this APP, we can see that most of the students have a basic understanding of the use of Liulishuo.

\subsubsection{The Relationship between Autonomous Learning of Liulishuo and English Learning}

The research has proved that the students have shown active learning in the use of Liulishuo. When scoring the APP, all the participating students said that in practice, the teacher's guidance in spoken English learning has a positive meaning. $78.57 \%$ of the students think that the teacher's suggestion is helpful in one aspect, but active learning counts more; and $35.71 \%$ of the students think that the teacher's suggestion is very helpful, and the students who participated in the research think that the teacher's suggestions make them improve faster. Compared with the results of the questionnaires of 489 North China Electric Power University (Baoding) English majors before the start of research, $21.43 \%$ of the students thought that using Liulishuo did not have much impact on spoken English, but played an important role in starting to speak. And without the guidance of teachers $7.14 \%$ of the students thought the APP did not help. Therefore, the use of Liulishuo does promote the independent learning of students.

\subsubsection{The Relationship between the Independent Sharing and English Learning}

Through Liulishuo, the student members insist on punching the card every day to practice oral English, share the daily dubbing results, and communicate in the online speaking group. The instructor can extract the dubbing data from time to time to explain the dubbing rules and analyze spoken English problems such as pronunciation and intonation in students' dubbings. At the same time, the information interaction between students and teachers gains a qualitative leap through the rapid, direct and effective way of sharing English dubbing. According to 489 English majors about what attractive characteristics Liulishuo has, 226 students say it is interesting to learn with and simple and easy to operate. And the rest say that the material is rich, and it has multi-functions. Therefore, with these conditions, through Liulishuo, students can share dubbing materials with each other through simple operations.

\section{Research Design}

In the discussion of how Liulishuo, with its own characteristics, meets students' practical demand of improving their oral English, we found that students had doubts about the actual efficacy of it. Therefore, in order to verify its efficacy in the improvement of students' oral English, and to explore the training mode of oral English ability supported by mobile technology, we designed an experiment and implemented it.

\subsection{Questionnaire}

At the beginning of this study, we took three steps to screen out representative English learning APP. First, make an open and comprehensive questionnaire. The options include 20 kinds of APPs that are already in the mobile application store used by the students. Second, randomly issue questionnaires to 489 students in North China Electric Power University (Baoding). Third, withdraw the questionnaire and analyze the results. The results showed that among the 20 APPs, 111 students, shared a total of $27.34 \%$ of the students, chose "Liulishuo", so we took it as the representative mobile Learning APP and the carrier for studying the practical efficacy of mobile APPs for spoken English.

\subsection{Voluntary Recruitment of Participants}

After identifying the subjects, we actively carried out a two-week recruitment campaign for students from North China Electric Power University in various forms such as posters and online notification sharing. With the statistical results, we found that although nearly 50 students from various majors signed up for voluntary activities, English majors accounted for the majority, and English majors included freshmen, sophomores, and juniors, which are more representative. Therefore, we chose 25 English majors to participate in the final practice verification.

\subsection{Grouping}

The grouping was targeted at the 25 chosen members, which is based on the grading standards of the CET Spoken English Test implemented by the National College English Test Committee since November 1999. This standard is divided into 4 levels as follows: A level: can communicate in English on familiar subjects with no apparent difficulty; B level: can use English to conduct smooth oral communication on familiar subjects though with some difficulties; C: can use English to conduct simple oral communication on familiar subjects; D: not yet have oral English communication skill. 
In the actual operation of the experiment, due to the limited actual evaluation conditions, the students rank themselves according to their actual situation. Among the students, 13 members identified themselves as Class B, and the remaining 12 students were Class C. In the study, group B and group C were compared with their first and second tests to form a comparison group. The experimental group was cancelled due to uncontrollable factors in actual operation.

In view of the fact that there is no overwhelming difference between the numbers of people in the two categories, the test results are comparable. It is reflected in the following: First, the same test of the two groups is comparable. The results of the later experiments also show that the scores of group B are higher, but they are not too far apart from the students of group C. Second: in the pre and posttests, the scores of the two groups all showed upward trend. Most of the students in Group B did not have a large fluctuation in their scores. Some of the students in Group $\mathrm{C}$ have obvious improvement in their scores. Third, the scores of the two groups tested in the early and late stages have also become a stark contrast. In the later period, compared with early period, the scores are generally showing an upward trend.

Grouping is not only for the comparison of data, but also to give the participants their hints and encouragement so that they can stimulate learning self-esteem in comparison, mutual learning and competition, so grouping is an indispensable part of the experiment.

\section{Experimental Plan}

This experiment adopts the experimental research program of comparison groups with pre- and post-test, which is divided into: pre-test, practice and post-test. The experimental flow chart is shown as chart 1.

\section{Experimental Plan}

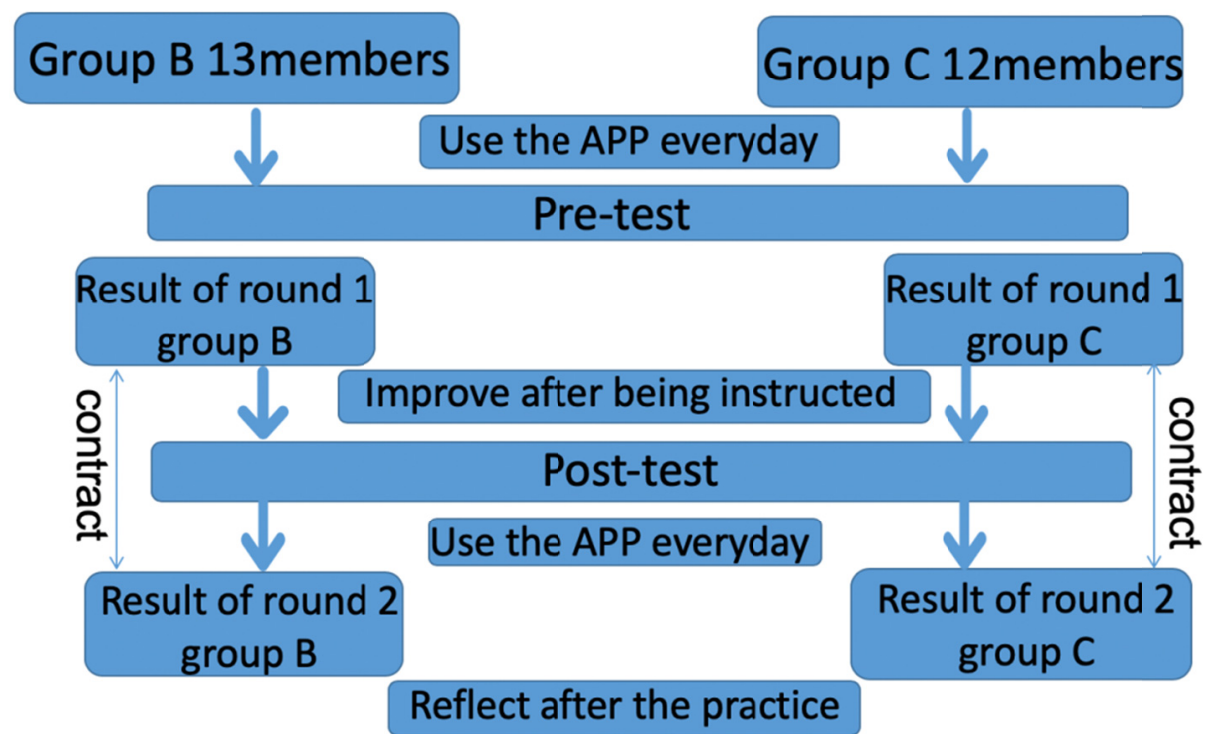

Chart 1. Experimental plan

4.1 Pre-Test

After one month of utilization of the Liulishuo to learn English daily, we obtain the results of first round with unified evaluation of spoken English using Liulishuo's own evaluation software.

\subsection{Practice}

Participants begin to use the chosen APP $\rightarrow$ Teachers give professional advice on pronunciation, intonation, pause, re-reading, etc. before students start dubbing, and give students guidance and remind them to practice carefully $\rightarrow$ After a multi-stage, multi-time dubbing practice, the students feedback to the teacher about the confusion and problems of using the APP during their practice. The teacher can test the dubbing, teach students 
in person and share her practice and experience with students in the QQ group. $\rightarrow$ When the entire English APP practice process is halfway through, we use the appropriate dubbing materials according to each person's different tone, and score them with same evaluation software to monitor the student learning process. $\rightarrow$ Teachers make a comprehensive summary, supplement the dubbing materials in terms of depth and breadth, and strengthen students' grasp of flexible use of spoken language. $\rightarrow$ Finally, we collect data, feedback, give students the opportunity to exchange learning experience, and achieve an efficacy analysis of the current English APP in improving spoken English.

\subsection{Post-Test}

After conducting the pre-test and using Liulishuo to practice spoken English for two months, the same evaluation software of Unified English APP was used to evaluate the students' oral English ability. The final round of results was obtained, and the practice lasted for 8 weeks.

\subsection{Control of Unrelated Variables}

In order to prevent the Hawthorne effect during the experiment, the students were not informed of the purpose of the experiment. Further, in order to ensure the consistency of the effectiveness of the teacher's commentary teaching, the two groups are provided guidance by the same teacher. In addition, in order to keep the learning content as consistent as possible, the researchers set up a daily network punching group to supervise the students to use the same English APP to learn daily. What's more, the study tasks and the overall learning of the two groups in the experiment were consistent.

\subsection{Data Collection}

Before the experiment began, the questionnaires were used to collect the data; in the pre-test, the unified evaluation software was used to quantify the scores to obtain the digital table comparison data; in the course of practice, two qualitative interviews were conducted. This includes asking students the following key questions in the form of a questionnaire: (1) Rate Liulishuo on a scale of one to ten? (2) Do you think it is helpful to use Liulishuo in English? (3) In practice, what is your evaluation of the teacher's guiding role? (4) Which aspect do you think Liulishuo has improved you?

\subsection{Methods of Data Processing and Analysis}

Collect test data and organize it through forms, line graphs and pie charts that can show the contrast visually and clearly. And the data processing and analysis method of this experiment draws on Wang Jijun's Experimental study on the ability of mobile learning to cultivate intercultural communication ability of college students. He also used the comparison group in his article and obtained effective survey data. The advantage lies in the stable and effective participants, and the research reports they make based on this research method are consistent with the facts and have reference. Therefore, the same test method we use also has certain practicality and credibility.

\section{The Necessity between English APP and Spoken English}

\subsection{The Current Situation of Oral English}

College English learning is an important way for college students to acquire English knowledge and skills, and it also plays a significant role in the cultivation of talents. However, the level of oral English in the college student population is uneven. Most students can only express very simple ideas, or, in another word, just a few words. When they encounter complicated situations, they are at a loss. The rapid social development and the intense competition require higher English speaking level of talents, so various innovative and reformative oral English methods have sprung up.

In term of education, the improvement of spoken English has always been a problem of Chinese college students. Most of them learned "dumb English" in their previous learning process, which makes the four major skill elements of learning English "listening", "speaking", "reading" and "writing" unevenly developed.

Psychologically, most college students have a mentality of quick success and instant benefit, without seeking to improve their English speaking level, but pursue the high scores of exams such as CET-4, and CET-6, IELTS, TOEFL and other exams. Over time, the competing attitude of peers mitigates the enthusiasm and innovation of students' spoken English learning.

On the learning process level, on the one hand, most of the students are passively involved in classroom learning, which makes the classroom interactive atmosphere very dull, where the teacher cannot have good interaction in the class, and the students do not further acquire knowledge. So the English learning is in a dead corner, with the students holding the mentality of completing the task, and unwilling to participate in class. On the other hand, students do not have a proactive attitude towards learning. In the course of learning, there will be a lack of 
persistence. There are many ways to learn spoken English, but those students who can persist in learning English are rare. Therefore, most of the students face the problem of giving up learning in the middle, not asking for a solution, and failing in improving spoken English.

\subsection{Thoughts on English Apps to Improve College Students'Spoken English}

In today's society, the concept of internationalization has gained its popularity with each passing day. As college students who are full of vitality and shoulder the great responsibility of the motherland's construction, how to deal with social competition, initiate new ideas of internationalization and achieve their dreams of life become the major concern.

The use of Liulishuo has its obvious advantages of being rich in material, easy to operate and convenient to use to facilitate students' autonomous learning. They improve themselves by imitating from the native speakers. With the contrast to the traditional classroom learning where the teacher focuses on the "reading" and "writing", the students do numerous exercises to learn English. The lack of "listening" and "speaking" combined study deteriorates domestic English learners' comprehensive ability. Therefore, the use of Liulishuo is a tool that can really make up for the shortcomings of the four unevenly-developed skills.

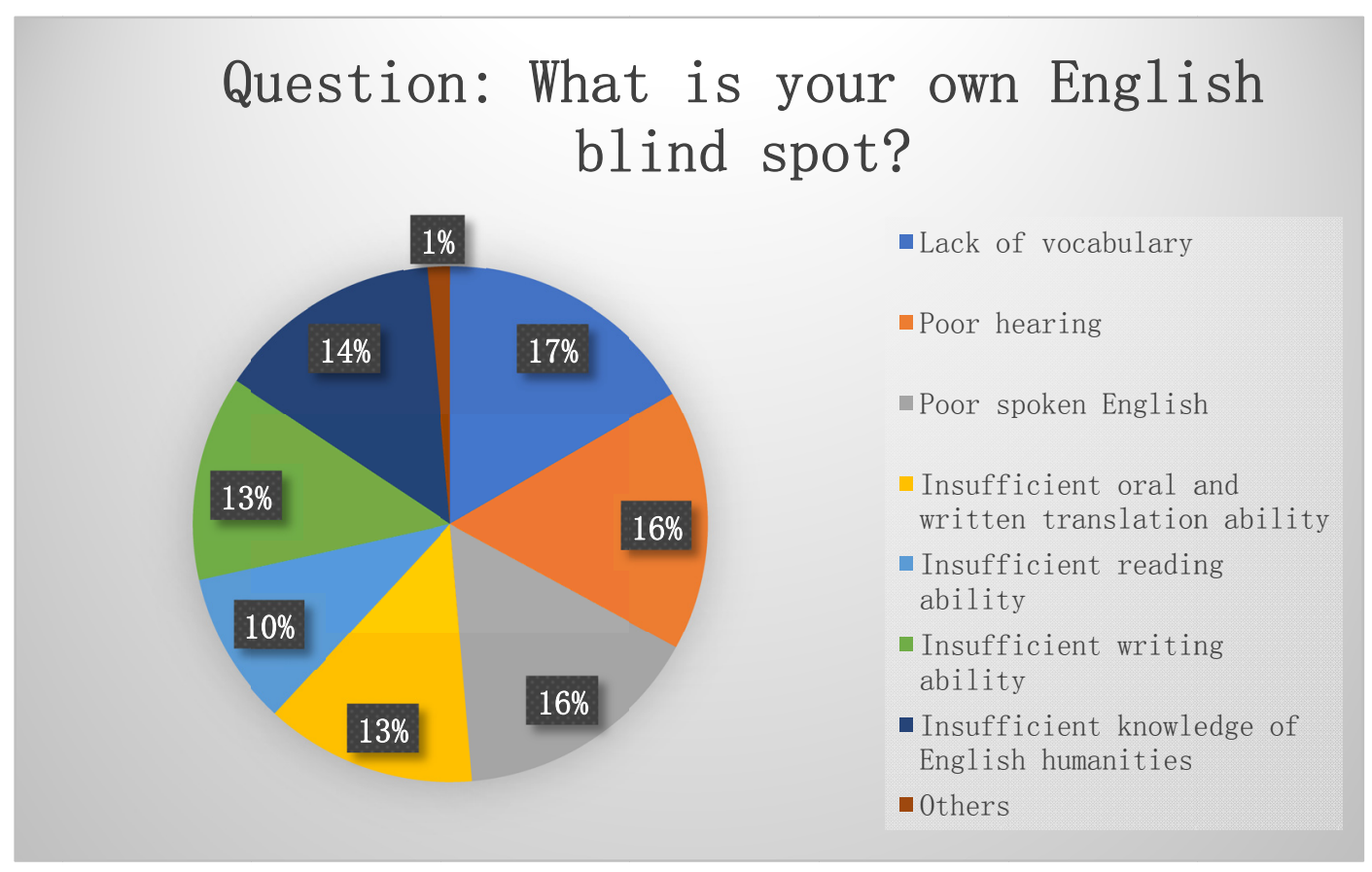

Figure 1. Questionnaire about students' blind spot in English learning

More specifically, the survey results in Figure 1 of 489 English majors in North China Electric Power University (Baoding) clearly show the problem of contemporary college students' spoken English in vocabulary, listening and speaking. And the students participating in the questionnaire are aware of the problems in their English learning process and show their willingness to actively change the status quo. So it has been proved that using the multi-functional Liulishuo, students become the master of their study and can positively improve their oral ability.

\section{Promotion Strategy Based on the Use of Mobile Apps to Assist English Learning}

The core of language learning is always the close combination of "listening", "speaking", "reading", "writing" and "translating". Grasping the learning needs of English learners should be the best strategy for the innovative service concept and broadening the service field. We should actively promote the use of English learning APPs like Liulishuo, because they can widen the horizon of contemporary college students' and improve their ability of adapting to the ever-changing domestic and international society, It can be said that English APPs have great significance in improving students' spoken English and the other four skills as well. 


\subsection{The Modern APP-Assisted English Class}

In the classroom, teachers act as guides. On the one hand, teachers can use the English APP to assign appropriate oral practice for students. At the same time, a free, open atmosphere is to be created, that is students can easily, quickly and effectively achieve the purpose of speaking English by using the English APPs. On the other hand, in their spare time, students can maintain online interaction with the teacher through the English APPs' punching function without the teacher's supervision. They can not only share their oral materials, but also get timely comments from the teacher. Over time, students are increasingly confident in using the APPs to practice spoken English, and there is significant progress in their spoken English.

\subsection{The Promotion of English Apps}

The English learning APP is a way of learning English on the mobile network that has just emerged in recent years. It is still relatively unfamiliar to most students or teachers. Therefore, it is essential to share and communicate to increase publicity and promote the English APPs' influence.

The English APP is a virtual way of learning, and it also relies on the virtual network world to spread its true influence. Students can use the convenient network connection and mobile devices to share their learning content and feelings in a timely and effective manner. The impact is not only reflected in the confidence in using English APP learning, but also in calling on people around them to follow the trend and enter a new mode of spoken English practice.

\subsection{The Future of English Apps}

In the era of mobile internet, college students are picky about the ever-changing application software market. It's hard to meet their demands with a single English-language APP for long-term learning. In this situation, English APP developers not only need to improve the fun of the APP, but also improve its versatility to meet the needs of students. Moreover, students should be encouraged to give feedback on the use of English APPs and promote the software performance. One can practice oral English with a variety of English APPs.

This kind of promotion strategy is also based on evidence. During the whole process, students spend most of their spare time using a single English APP, Liulishuo. Therefore, in the feedback, half of the students think a single APP too boring, and it would be better to be diverse.

\section{Conclusion and Outlook}

\subsection{Analysis Conclusion}

The research of this project proves that adopting English-speaking APPs that are favored by modern college students (in the case of North China Electric Power University, Baoding), and under the guidance of teachers, it can verify the positive effectiveness and practicability of active oral English practice to improve the spoken English, and its actual utility can be reflected by the improvement of two results of students' using the evaluation software for testing. In the first test score, everyone was above 75 points out of 100 points, and the majority scores over 80 points. Although the second score was not completely counted due to the actual uncontrollable factors, the overall score did not change much, but some students improved significantly. Therefore, from practice, we can conclude that the use of Liulishuo is important for future college students to improve their spoken English ability through independent learning.

\subsection{Research Deficiency and Outlook}

The problems in the implementation of the research include: personnel problems. The actual number of organizational personnel is insufficient, and due to the limitations of the participants, and the local uncontrollable objective factors at the time, the "control group" of 20 people "in the original plan was canceled during the process of the research. In this regard, we expect that before the next in-depth study, we can organize the personnel in advance and reduce the impact of objective factors. As for App problem: the background operation mechanism of Liulishuo is not perfect, there have been 2-3 times of dubbing interface blank situation, and we look forward that, in the in-depth study, we can increase the type and number of spoken English APPs, Scale-out test for the practicality and effectiveness of oral English for students with spoken English Apps using mobile devices as a carrier.

\section{References}

CNNIC. (2014). Retrieved from http://www.cnidp.cn/

Dou, J. (2014). Sports-based mobile micro-learning application research-Taking job-seeking skills and high-level English teaching as an example. 
Fei, J., \& Guo, M. (2015). The Influence of Mobile APP on College Students' English Learning. Brand, 2015(02), 25-27.

Hou, Y. (2015). Using Mobile Tools for Language Learning--A Study Based on Yantai University. Anhui Literature, 2014(03), 130.

Huang, R. (2008). Mobile Learning: Theory, Current Situation and Trends. Beijing, Science Press

Li, Y., \& Zhai, S. (2010). The Status Quo and Development Trend of Domestic Spoken English Research. Foreign Languages in China, 7(06), 85-91.

Liu, Y., \& Zhai, S. (2004). Mobile Learning-A Review of the Status Quo of Foreign Studies. Modern Educational Technology, 2004(03), 12-16.

\section{Copyrights}

Copyright for this article is retained by the author(s), with first publication rights granted to the journal.

This is an open-access article distributed under the terms and conditions of the Creative Commons Attribution license (http://creativecommons.org/licenses/by/4.0/). 